\title{
'Mind Your Business and Leave My Rolls Alone': A Case Study of Fat Black Women Runners' Decolonial Resistance
}

\author{
Garcia Ashdown-Franks 1,2 (D) and Janelle Joseph ${ }^{2, *}$ \\ 1 Institute of Psychiatry, Psychology and Neuroscience, King's College London, De Crespigny Park, \\ London SE5 8AF, UK; garcia.ashdown.franks@utoronto.ca \\ 2 Faculty of Kinesiology and Physical Education, University of Toronto, Toronto, ON M5S 2W6, Canada \\ * Correspondence: janelle.joseph@utoronto.ca
}

check for updates

Citation: Ashdown-Franks, G. Joseph, J. 'Mind Your Business and Leave My Rolls Alone': A Case Study of Fat Black Women Runners' Decolonial Resistance. Societies 2021, 11, 95. https://doi.org/10.3390/ soc11030095

Academic Editor: David Brown

Received: 31 May 2021

Accepted: 29 July 2021

Published: 11 August 2021

Publisher's Note: MDPI stays neutral with regard to jurisdictional claims in published maps and institutional affiliations.

Copyright: (c) 2021 by the authors. Licensee MDPI, Basel, Switzerland. This article is an open access article distributed under the terms and conditions of the Creative Commons Attribution (CC BY) license (https:// creativecommons.org/licenses/by/ $4.0 /)$.

\begin{abstract}
The Black female body has been vilified, surveilled, and viewed as 'obese' and irresponsible for centuries in Western societies. For just as long, some Black women have resisted their mischaracterizations. Instead they have embraced a 'fat' identity. But little research has demonstrated how Black fat women participate in sport. The purpose of this study is to show how Black fat women who run use social media to unapologetically celebrate Blackness and fatness. This research uses a case-study approach to illuminate a broader phenomenon of decolonial resistance through running. In addition to analysis of websites, blogs, and news articles devoted to Black women's running, we discuss the (social) media content of two specific runners: Mirna Valerio and Latoya Shauntay Snell. We performed a critical discourse analysis on 14 media offerings from the two runners, including websites, Twitter pages, and blogs collected over a five-month period from September 2020-January 2021. The analysis examined how they represent themselves and their communities and how they comment on issues of anti-fat bias, neoliberal capitalism, ableist sexism, and white supremacy, some of the pillars of colonialism. Whereas running is often positioned as a weight-loss-focused and white-dominated colonial project, through their very presence and use of strategic communication to amplify their experiences and build community, these runners show how being a Black fat female athlete is an act of decolonial resistance. This study offers a unique sporting example of how fat women challenge obesity discourses and cultural invisibility and how Black athletes communicate anti-racist, decolonial principles.
\end{abstract}

Keywords: critical discourse analysis; women; sport; running; decolonize; fatness

\section{Introduction}

For centuries, the fat body has been vilified, surveilled, viewed as diseased and gluttonous, as well as characterized as risky and irresponsible. These negative misrepresentations are amplified for fat Black women. Yet, for centuries, fat Black women have resisted knowledge produced about them from outside their communities. Their own definitions of health, sport, nutrition, and beauty have been based on alternate epistemologies to dominant medicalized, Western knowledge systems. This paper provides a historical and social context for various representations of 'obesity' and fat Black women before offering a case study of fat Black women who run and share their experiences on social media. In addition to a critical discourse analysis of websites, blogs, and news articles devoted to Black women's running, we examined 14 media offerings from two runners: Mirna Valerio and Latoya Shauntay Snell. We examined their websites, Twitter pages, and blogs collected over a five-month period from September 2020-January 2021. The results of this study show that female athletes are using social media to comment on anti-fat bias, neoliberal capitalism, ableist sexism, and white supremacy, some of the pillars of colonialism.

Importantly, and in line with Mignolo, we use the term 'decolonial' to highlight a refusal to accept colonial knowledge systems. Decolonial resistance includes epistemic disobedience or a "delinking from the web of imperial/modern knowledge and from 
the colonial matrix of power" [1] (p. 178). The colonial matrix created knowledge about sport and bodies, presented as rational and neutral so as to hide their racist and sexist origins; decolonial resistance, therefore, requires "the (re)iteration, (re)interpretation and (re)presentation of the meanings of muscle, bone, fat and skin-the materiality of the body itself" [2] (p. 9). Whereas running is often positioned as a weight-loss-focused and White-dominated colonial project, through their very presence and use of strategic communication to amplify their experiences and build communities, these runners show how being a fat Black woman runner is an act of decolonial resistance.

\subsection{The 'Obesity Crisis' and Fat Studies}

In recent years, at least three approaches to research on the fat body emerged. First, some research reflected a so-called 'obesity crisis,' which has become a major public health concern. As described by Syed, "alarmist views of obesity have, over the years, escalated to anti-obesity hysteria" with links made between 'obesity' and cardiovascular problems, arthritic conditions, mental health co-morbidities, economic costs to society [3] (p. 1), and as Lewis et al. note, stigma to individuals and communities that constrain leisure physical activity participation [4]. The positivistic, biomedical view of 'obesity' pathologizes individuals and assumes that it is a disease caused by a combination of over-eating and under-exercising. Extensive research that posits that an estimated $80 \%$ of Black American women are 'overweight' or 'obese' [5] and that African American women experience the highest rates of 'obesity' compared to any other subpopulation in the United States fails to recognize the broader material and social issues connected to 'obesity' [6]. Those in the biomedical field might attribute a Black woman's higher weight to a lack of willpower and self-control when it comes to diet and exercise. The emphasis on personal responsibility for one's weight not only among the medical community but also in the general public positions 'obesity' as one's own fault, as directly related to ill-health, and as inherently, individually, and morally bad.

Meanwhile, there is a second area of health research that recognizes broader social determinants of health, such as ethnicity, migration, acculturation, socioeconomic status, geography, and exposure to stress [7], as well as nutrition and access to healthy food and medical services, when considering the causes of weight-related diseases and disproportionately high rates of 'obesity' among Black women [8]. The social determinants of health field shifts the blame from individuals to the structures in which they are embedded. However, some of these health professionals continue to see larger bodies as (having) a problem. In this context, rather than viewing human beings as coming in a range of sizes, 'overweight' is problematized, which allows anti-fat bias to flourish.

The third area of research, aligned with the fat acceptance movement, uses the term fat rather than 'obese' to more neutrally describe individuals in larger bodies [3,9-11] and rejects the negative stereotypes and assumptions associated with both medicalized terminology and the word 'fat' [12]. Fat Studies is often viewed as a radical academic field founded on refusing the medicalized conceptions of 'obesity' and reclaiming the word 'fat' to reinforce identity and pride $[3,13]$. Scholars in the area of fat studies point to biomedical approaches toward 'obesity' for constructing a pathologized body: the 'obese' Other [3]. Instead, scholars of fat studies draw theoretical tools from Black feminism in recognizing the ways in which fatism, or anti-fat bias, interacts with other social oppressions such as racism, sexism, and ableism, creating multiple, compounding axes of discrimination [14,15]. Hill Collins notes the medical field has played an important role in perpetuating supposedly "scientific and common-sense beliefs about bodies, fitness, evolution, reproduction, science and the state, as well as about ability, race, ethnicity, gender sexuality, age and nation" [15] (p. 255). These ideas have historically coalesced to define health and constructs of (ab)normality in intersectional ways: "a fat studies approach offers no opposition to the simple fact of human weight diversity, but instead looks at what people and societies make of this reality" [10] (p. x). The Health at Every Size (HAES) movement suggests concerns about weight should be de-linked from concerns about health and vice versa [16]. 
Chastising a large person, Taylor notes, is "a body shame tactic...more likely about the ways in which we expect other bodies to conform to our standards and beliefs about what a body should or should not look like" [11] (p. 21). This tactic is ableist and used in misogynist and racist ways to erase fatness and blackness from Western aesthetics and beauty standards [17].

\subsection{Anti-Fat Bias and Neoliberal Capitalism}

Beyond health and aesthetics, fatness and blackness are linked to morality, happiness, and responsibility in the Western imagination. The notion of the fat Black woman as an irresponsible mother, specifically, exemplifies 'misogynoir' a term coined by Bailey to capture "the co-constitutive, anti-Black and misogynistic racism directed at Black women, particularly in visual and digital culture" that combines "misogyny, 'the hatred of women,' and noir, which means 'black' but also carries film and media connotations" [18] (p. 2). Specifically, Black women in the United States, who live in worlds steeped in anti-Blackness and coloniality, experience (in)direct violence against their bodies, often with an emphasis on fat-phobia or anti-fat bias [17]. This bias was born out of "protestant moralism and the disdain of indulgence" since as early as the 18th century [19] (p. 209), when an understanding of fat bodies was projected onto 'Africans' as perverse and wrong, allowing the French and British to engage in a form of abjection to rein in their own bodies [20]. This fat and Black rejection continued into racial scientific literature before making its way into the medical field most recently [19]. Strings goes on to explain how the development of the thin White ideal was essentially predicated upon an image of the fat, diseased Black woman to "both degrade black women and discipline white women" [19] (p. 211). It is no wonder, then, that a fear of being fat is so widespread and common now in the West.

Understanding the present-day context of anti-fat bias or stigma requires analysis of the influence of neoliberal capitalism in the dieting and running industries and their role in framing 'obesity' as a failure of morality, a lack of discipline, and an inability to 'progress' [21]. Fox explored how the Western desire for transformational weight loss (and thereby for temporal progress) is a reflection of 'colonial temporality' [22]. Within coloniality, Rose similarly argues, colonizers' grasp of temporality and need for improvement formed the foundation for "their vision of a future that will transcend the past", altering the colonizers' sense of time so much that it enabled them to "understand [themselves] in an imaginary state of future achievement" [23] (p. 17). Fox argues that dieters "experience their lives according to these forms of time" [22]. In this way, temporality based on colonialism has resulted in a focus on the body in particular futures, essentially voiding its value in the present [22].

Running, too, has been described by Bridel and Rail as a future-oriented means to "lose weight, to change body shape, or simply to become "healthier," each of which was positioned as having aesthetic implications" [24] (p. 135) for a "sleek and thin" look [24] (p. 136). Using these logics, in spaces where Black futures are intentionally circumscribed, limited, and made fungible through state apparatuses that deny futures [25], the large Black present body exemplifies a complete rejection of colonial temporal progress frameworks. Whereas the imperatives of whiteness and slimness create "an ideal state of embodiment" [17] (p. 9), requiring the rationality and self-discipline of "the perfect subject-citizen [who] is able to achieve both eating and thinness ... [as] out-of control consumer and self-controlled subject" [21] (p. 444). Black women running to lose weight become viewed as moral, worthy, exercising discipline over their bodies, and personally sharing the burden of governance with the state [26]. A study of neoliberalism, soul food, and diet among Black women found that:

Black women who are physically active, on diets, undergo gastric bypass surgery, or publicly announce a weight loss strategy are increasingly deemed, within the context of neoliberalism, to embody a rationality and self-discipline (read: Whiteness) that those who are fat (and poor) lack. [27] (p. 807) 
Thompson questions, then, whether the woman is still resisting both whiteness and slenderness, if she becomes a dieting Black woman and, similarly, if a fat Black woman becomes active, for the purpose of losing weight, is she still resisting neoliberalism [27]? Beyond these questions, we wonder, how do those who are physically active but without the goal of losing weight fit into (or resist) this neoliberal, colonial society?

\subsection{Colonizing the Black Female Body and Running-Historical Perspectives}

Present-day Western aesthetic standards and discourses about fat Black women did not suddenly emerge. They have been shaped by powerful actors over a long historical period. Shang explains that the colonized body has meaning defined by the colonizer who:

Imagines himself [sic] as endowed with the priority to speak for the other, ...

to invest the other's body with epistemic difference [which] would characterize the manner in which the body of the native is eventually thingified and objectified under the exigencies of colonial "modernity" and "civilization". [28] (p. 145)

The institution of slavery as a primary tool of colonization was essentially contingent upon the existence of this objectified Other. Indeed, Black feminist theory posits that the devaluation of Black women in the United States and globally is rooted in the institution of slavery, in which Black female bodies were routinely violated for the profit and pleasure of others [29,30]. The idea of Black women's over-sensualism proliferated through controlling images such as the hypersexual 'Jezebel' or 'Sapphire' [31]. This hyper-sexuality, as Awad and colleagues explain, derives from women's construction "deserving of sexual exploitation or as breeder women lawfully usable for populating owner's [sic] plantations with new slave stock or for the generation [of] revenues" [30] (p. 1). Racialized and gendered intersections of privilege, oppression, and power cast the Black woman as prone to sexual and oral indulgences [32]. This idea of Black women's sensualism is now used in the present day in relation to eating and 'obesity' to frame Black women as a threat to public health [32]. Both Strings and Forth suggest that the concept of Black oral insatiability is distinctly misogynist-typically placing Black women, rather than men, at the center $[20,32]$. Thus, there has always been a particularly racialized and gendered element of anti-fat attitudes.

The story of Sartjie Baartman is perhaps the most shameful and well-documented individual example of how anti-fat attitudes were racialized and gendered through colonial practices. Sartjie Baartman was Khoisan, born in 1789 in South Africa. In 1810 she was asked by her then captors, for whom she worked as a servant, and an English ship surgeon, to come to England, according to Mattoscio [33]. It is unclear how informed Sartjie was about what was to be the true purpose of her time in England, but records show she entered into a specious contract to "share in the profits made on her exhibition in Europe" by Dutchman Henrik Cezar [34] (p. 90). Baartman had what the colonizers viewed as a fascinating, inferior, and oversexed body due to its size and her "unusually large" buttocks [34-36]. Sartjie arrived in England, where she became a spectacle, half-clothed in a cage, in London's Piccadilly circus. She would eventually be moved to France in 1814, where she worked for a man who showcased animals and treated her as such, forcing her to perform shows for private audiences. In both England and France, Saartjie was ridiculed and commodified, while her British and French superiors exploited the financial reward of her body as a spectacle [35]. Usiekniewicz highlights how Sartjie's legacy formulated the notion of "Black fatness" as "a sign of degeneration" and "different manners of body policing" that are still to this day perpetrated on those living in fat, racialized bodies [37] (p. 12).

The rejection of racialized fatness is further explained in the findings of the 19th century Western ethnographers and travelers:

In such cases, fat was not simply a reference to body size and shape butwas viewed as a tangible example of softness, looseness and even greasiness, reflecting the sensuality, indolence, and other moral defects often attributed to such peoples. In this way, it performed a cautionary function for Western elites themselves, especially in relation to the beauty of women. If becoming corpulent was 
identified as a problem of health, beauty and morality, to admire or desire fat was to deviate from ... the core values of Western civilization as a whole. [20] (p. 215)

This understanding of fat as primitive and morally wrong perpetuated a 'colonial subtext' to growing Western anxieties around fatness in the 19th century and contributed to the present-day cultural obsession with slimness alongside a disgust for fat [20].

Another element of the colonial subtext was the use of sport, particularly running, to control fatness. Bale explains that Western anxieties fueled the elevation of Eurocentric cultural knowledge, curricula, sports, and ideals as political tools used to facilitate colonial expansion [38]. The idea of an attractive archetype of a "distance running body": lean, muscular, toned, slight but strong generated through modifying the body through running, transcends geographies [39], although many communities "resist these dominant stereotypes and challenge ideas of properly disciplined bodies" in running [24]. For example, in the Clydesdale community of fat runners in the United States "who do not have normative bodies but continue to run", the idea of a fat, attractive running body remains a chimera [40] (p. 137). In sum, the colonial imagination of fat, Black, colonized, unfit, 'other' women has been used historically and in contemporary times to simultaneously degrade and discipline the Black woman.

\subsection{White Supremacy, Contemporary Black Body Image, and Black Feminist Mediated Resistance}

The thread that links these body ideals from the colonial past to contemporary times is that of white supremacy. Sanders goes so far as to argue that the political, cultural, and public health discourses that emphasize high rates of 'obesity' among Latina and African American women are a contemporary 'racial project' that serve to strengthen white normativity [41]. Gentles-Peart contends that the association of slimness with whiteness is still present in contemporary Eurocentric femininity [42]. This can be seen when the American news media associate anorexia with young, white women but 'obesity' with racial minorities [43]. Indeed, in an article illustrating how the Western medical system has catered to Whites and perpetuated societal understandings that eating disorders are a 'white woman's problem,' Mikki Kendall, a Black American woman who experienced an eating disorder as a child, explains how her anorexia went largely unnoticed or even applauded by those around her. "The narratives that position the curviness of Black girls' bodies as a warning sign of future 'obesity' will lead them to congratulating you on watching your weight instead of grasping that there is a problem playing out in full view" [44] (p. 113). Black women and their issues often remain invisible.

Gentles-Peart notes that this European aesthetic is overvalued in mainstream culture, while Black female bodies have largely been devalued [42]. In the United States, features such as white skin, blue eyes, and blond hair are viewed as beautiful, while features more closely resembling the African aesthetic are viewed as undesirable or ugly [30]. These ideas are communicated through media, beauty, fashion, and fitness industries. Shang notes that when examining representations of power, "body image is most apt in revealing and interrogating the various transformations of discourses of difference that account for power inequality, hegemonic relations and political exclusion" [28] (p. 151). Indeed, when considering that "Black women are less attractive is a message that is transmitted daily and from multiple external forces or social institutions", white supremacy prevails in maintaining such discourses of difference and inequality [30] (p. 2). It is in this context of such ever-present white supremacy that this case study is situated.

Any literature review of white supremacy and Black women's body image would be remiss if it did not also examine Black women's resistance to oppression. Black feminism was born in response to a lack of antiracist and antisexist politics in feminist, Black liberation, and civil rights movements $[29,31,45]$. Black feminist theory encourages multiple ways of knowing, privileges personal testimony, and reveals Black women's ongoing resistance [31]. Importantly, Black feminism-as a critical paradigm-focuses on structural, institutional, and cultural oppression, clarifying mediated power relations rather 
than individual oppressive acts $[35,46]$. Many Black feminist scholars have demonstrated that Black women experience 'protective factors' against body image disturbances $[47,48]$ and, for some, a disdain for the thin ideal as a marker of good health and positive body image [49]. An important means of resistance in the 21st century is the ways racialized women mobilize social media platforms to document the misrepresentation of racialized bodies in mainstream media, to raise awareness about injustice in their communities, and to share experiences [50,51]. Particularly relevant to the case studies presented below, social media has afforded many Black women an opportunity to directly engage with social activism online, rendering visible their experiences through "protesting misogyny, racism, and homophobia when they see it" [52] (p. 111), and "practicing self-care in active synchronous and asynchronous public ways" [53] (p. 367). Razack and Joseph's study focused on Japanese-Haitian-American tennis player Naomi Osaka's media representations and built on the concept of 'misogynoir' [54]. Razack and Joseph show that an athlete's own social media can provide insights regarding their body image and their resistance to dominant representations of race, gender, and the body, specifically using Twitter to offer "a comedic resistance against misogynoir" [54] (p. 12). Building on these studies, we examine the intersection of anti-fat, anti-woman, and anti-Black bias, using the (social) media of two women runners who turn their invisibility and misunderstandings of their identities into hypervisibility through imagery and text.

\section{Materials and Methods}

This case study examines the representations of the Black female body, the sport of recreational running, and the role of white supremacy and Black fat resistance in both. More specifically, this case study explores the representations of Mirna Valerio and Latoya Shauntay Snell, two self-identified fat, Black women runners, primarily from their personal publicly available media (Instagram, Twitter, and personal websites) and their contributions to mainstream news media. We examined all of the social media content produced by the two runners over a five-month period from September 2020-January 2021 (approximately 800 posts), ultimately choosing 14 on which to perform a critical discourse analysis.

Critical discourse analysis as a methodology focuses on the use of language and the discourses within it and on understanding how knowledge is shaped through such discourses [55]. While it has been used in sport studies to analyze interviews [56], newspapers [57], and magazine articles [58], critical discourse analysis remains underutilized to analyze social media related to sport. Given this, there have been calls for critical discourse analyses of "'new' media texts" related to sport to understand "how these construct certain identities and the practices linked to them" [59] (p. 241). These analyses may ultimately "be useful windows into understanding the taken-for-granted discourses that frame and form cultural identities ... and the psychological and behavioural implications" [59] (p. 241) within sport, leisure, and physical cultures.

The critical discourse analysis presented below examines how Mirna Valerio and Latoya Shauntay Snell represent themselves and their communities and how they comment on issues of decolonizing race, gender, and size [60-63]. Other media, including mainstream American news outlets, interviews, and podcasts focused on fat Black women (athletes), are explored alongside academic works to examine these concepts. Through the lenses of fat studies and Black feminist theory, it will be argued that choosing to run without the aim of personal transformation or weight loss, and choosing to refuse erasure by discussing fatness publicly, are acts of decolonization.

\section{Results}

\subsection{Running While Black}

The results of this study demonstrate that running while black can come with risks. In her New York Times opinion piece, "Jogging Has Always Excluded Black People," MehlmanPetrzela details the white origins and racist tropes associated with running. They cite recent research that "found under $10 \%$ of frequent runners identify as African-American-they've 
also been relentlessly depicted as a threat to legitimate, white joggers" [64] (para. 5). In turn, as Mehlman-Petrzela explains, "[n]othing solidified this notion of the black threat to white joggers as viscerally as the case of the "Central Park jogger," when five men of color were wrongfully convicted of raping and attempting to murder a white runner" [64] (p. 3). This exemplifies Razack's contention that the ghost of slavery permeates institutions such as policing, highlighting "the disposability of Black bodies" [65] (p. 17). Furthermore, she argues that settler colonialism dispossesses and simultaneously "preserves intact its colonial, spatial and legal structures" [65] (p. 17), thereby excluding Black bodies from many sport or leisure spaces (professional basketball, American and association football, and boxing are notable exceptions) while disproportionately including them in spaces such as carceral institutions. While it is sadly all too well-documented that women do face safety concerns while running, this has meant that the safety of Black runners has largely been overlooked and viewed as less important in these discussions.

Two other specific cases highlight extreme examples of white supremacy and the inaccuracy of the notion that white women runners are the only ones for whom safety is a concern. In Salt Lake City in 1980, four friends (two Black and two White) were out for a jog together in a local park. A white supremacist, vehemently against racial mixing, approached them and gunned down the two Black male runners, David Martin and Ted Fields. More recently, in 2020, the shocking murder of Ahmaud Arbery, a young, Black runner in Georgia, reminded us that running is a sport plagued with racism. By presenting these cases, Mehlman-Petrzela highlights that rather than a sport for "everyone ... the most enduring legacy of the racialized experience of recreational running is the surveillance and suspicion to which Black people have long been subjected" [64] (para 17). This over-surveillance and over-suspicion of Black runners may be understood as part of a broader increase [in "racial targeting and racial profiling of groups seen as 'posing a threat" to the public [66] (p. 173)." Indeed, 'surveillance' is defined as a means to make visible the identities and conduct of individuals under scrutiny [67], with the 'gaze' serving to dehumanize the observed [66]. The discourse of security and the politics of visibility are inextricably linked, with this discourse serving to hyper-visibilize "issues of crime and the enemy", while simultaneously rendering issues of exclusion and inequality invisible [66] (p. 174). Following the death of Ahmaud Arbery this year, many Black runners shared stories relating to this surveillance and suspicion. Indeed, Latoya Shauntay Snell spoke on a podcast and a webinar advocating for the need to consider intersectionality alongside running safety. Latoya Shauntay Snell has been verbally attacked both in-person while running and online, where she posts about running. Though she may not (always) be seen as a threat to others on the street as many Black men are, it has been suggested, due to her size, that she caused her son's Type 1 diabetes, and she is, therefore, a threat to the next generation [68].

In the light of ongoing white supremacy, both generally in their communities and specifically within running communities, Black women running can enact decolonial resistance. Indeed, running as a way of resisting the continuing effects of colonialism has been described in the Kenyan context [38,69] and among Indigenous Canadian women [70]. Specifically, the authors described how Indigenous women "further challenge settler colonialism by not succumbing to chronic diseases or physical inactivity" and by regenerating their community connections [70] (p. 212). In this way, the existence and growing popularity of running groups made up of Black women, such as Black Girls Run and Black Girls Do Run, allow women and girls to challenge colonialism by not succumbing to physical inactivity [71,72].

A description of Black Girls Run's mission, taken from their website, provides various statistics from the U.S. Department of Health and Human Services Office of Minority Health. These include rates of 'overweight' and 'obesity' for African American women and girls in comparison to other racial groups in the U.S. Their aims go on to elaborate: "We can make a lot of excuses as to why these numbers are the way they are, but excuses never solved an epidemic ... There's a lot to talk about and a lot of calories to burn, so 
be sure to sign up for automatic alerts and join your local group" [1] (para. 3). Though the organization's aim to get more Black women active is important and commendable, it appears as though this particular organization has internalized and thus endorses colonial and Western biomedical understandings of 'obesity'. This can be seen in the way they frame Black women as individually responsible for making 'excuses,' describe 'obesity' as an epidemic, and discuss calories as needing to 'burn.' Not every Black women's organization is pro-fat. In fact, Aitchison contends that leisure is an area in which power is created and exercised and can thus mirror racial or gender-based oppressions that are seen in other societal institutions [73]. Thus, applying a Black feminist perspective to leisure research allows us to examine the different ways "leisure 'choices' may be created for, by, and with Black women" [35] (p. 646). While leisure, and specifically running, is often viewed as an accessible activity, available to all, some Black women may experience limitations in their inclusion or opportunities to "resist or express leisure as others may, hence, some of the roles in leisure may only compound their placement in society" [35] (p. 646). Thus, a Black feminist perspective on running can be used to analyze why some women may not be able to engage in resistance at all, why others may do so by joining groups such as Black Girls Run, and why Mirna Valerio and Latoya Shauntay Snell are able to resist in their public ways, motivating others to do the same.

\subsection{Running as Decolonial Resistance: Against Colonial Temporality and towards Visibility}

Latoya Shauntay Snell and Mirna Valerio are two self-identified fat runners currently living in the USA. Latoya Shauntay Snell, who describes herself as a fat, Black, queer woman with a disability (endometriosis, among other conditions), openly speaks about her ongoing journey with her body and physical activity. After her doctor warned her at the age of 27 that if she did not change her lifestyle and lose weight, she would not live much longer, she initially gave up on herself before deciding to get into cycling and then running. Having lost nearly 100 pounds in a year through running and limiting her diet, she continued to be body-shamed in a range of in-person and online contexts and suggests that this shaming played a role in her subsequent development of an eating disorder. After a particularly traumatizing experience where she fainted from lack of food and ended up in the hospital emergency room, Latoya Shauntay Snell realized that she had to fixate on why she ran rather than on her weight. As Jenny Mccoy explains in a Runner's World feature of Snell: “Turns out, it wasn't about losing weight. It was about all she had gained through the sport: friends who felt like family, amazing travel opportunities, and the ability to speak up and advocate for herself" [74] (p. 7). Latoya Shauntay Snell continues to advocate not only for herself but also for the Black community, those living with disabilities, and those of color: "I' $\mathrm{m}^{\prime} 31 / 2$, a loud mouthed runner, passionate activist that don't do fatphobic, homophobic, ageist, weight loss or sexist commentary" [63]. On her Instagram biography, Latoya Shauntay Snell characterizes herself as the Founder of Running Fat Chef, a journalist, speaker, activist, and runner.

Similarly, Mirna Valerio is not focused on losing weight and proudly shows that one can be both fit and fat. She self-describes as a runner, a speaker, and an author on her Instagram page and, on her personal website [60], she mentions experiencing a health scare in 2008, which reignited her love for running after having been a runner in high school. She created Fatgirlrunning, a blog about living as a bigger woman in a world of thin athletes. Like Latoya Shauntay Snell, Mirna Valerio understands how difficult it can be for some in the running and fitness community to accept fitness with fatness. In an interview with Runners World, she explains:

Serious running and being seriously fat just don't go together in people's minds. If I didn't run, I wouldn't draw notice. I'd just be one more obese black woman. And if I were thin, I'd just be one more number at the starting line. But I run a lot, and I'm still fat. Some people can't get their heads around that. They don't think $\mathrm{I} m$ for real, that I've earned the right to call myself a runner. [75] 
Mirna Valerio and Latoya Shauntay Snell challenge colonialism as runners living through and with white supremacy; they simultaneously reject Western biomedical ideals, sport standards, and ideas of what fat bodies can do. Latoya Shauntay Snell and Mirna Valerio share some of their frequently used hashtags in common, such as \#fatrunner and \#plussizeathlete, with nearly 200,000 combined followers.

Colonial notions of temporality emphasize the need for change, for progress, for improvement. "Dieting 'before' and 'after' pictures hold "us hostage to a future that will never materialize while simultaneously making other ways of experiencing time unthinkable" [22] (p. 217). Running is similarly steeped in a singular discourse of future body transformations through regular self-discipline. In our Western society, in which the so-called ideal body is that of a thin white woman, achieving this body would be a sign of supposed improvement and progress for a fat Black woman [19]. Mirna Valerio and Latoya Shauntay Snell, by actively and publicly choosing to accept and celebrate their bodies in their present state, defy these colonial pressures to change. They share pictures, but the improvements they gain and the progress they experience relate to expanding their online communities and increasing advocacy for anti-racist, crip, queer, and feminist causes. This is made evident through the women's engagement in social media, as well as other forms of knowledge sharing such as websites, workshops, and interviews in which they engage that celebrate fitness and fatness and offer transparency about their relationship to food, emotions, and resistance practices.

\subsubsection{Celebrating Fitness and Fatness through Representation}

Both Mirna Valerio and Latoya Shauntay Snell are active on Twitter and Instagram and post a wide range of content, from food to workouts to their takes on political issues. On various online websites, the two women are often commended for their work and promoted alongside the social media accounts of other similar activists. Latoya Shauntay Snell was recently mentioned in an article by Essence magazine titled 5 Inspiring 'Curoy Fit' Influencers We're Following (and Loving!) [75], and in Glamour magazine's Love Your Bod: 31 Inspiring Fitness Women to Follow on Instagram [76]. The Essence article introduces her by saying: "Who says size matters when it comes to running? Latoya Shauntay Snell has proven that you can get up and hit the pavement at any size." Essence magazine appears to echo her views on the body, starting the article by noting that fitness cannot be inferred simply from looking at one's body and that size does not equate to strength or to health [75]. Through her Tiktok videos and interviews on running podcasts such as the Grounded Podcast with Dinée Dorame, Latoya Shauntay Snell inspires and challenges her broad and young audience to defy stereotypes of 'obesity' to try new physical activities, and to reject worries about failure. Mirna Valerio was also recently highlighted in Global Sport Matters' 10 People to Follow in 2021 [77]. As Kendall Jones explains in that article, Mirna "emphasizes the importance of incorporating intersectionality across sports to create space and challenge standards of athleticism and beauty which are rooted in racism" [77].

When her achievements are celebrated in mainstream media, Latoya Shauntay Snell grapples with issues of performative inclusion and tokenism. In November 2020, she tweeted: "it would be nice to know that the work that you're doing only scares you because it's different or pushes change-not because you're tokenized" [62]. A few days later, she published a series of tweets regarding the news that she had recently been one of four individuals on the cover of a Runner's World magazine. In one, she says thanks to Runner's World:

for showing more than just me: My neighborhood; 3 other cover versions of people who DON'T look like me; a chance for people to see a version of themselves. Please continue to expand + explore stories of countless others: We need to see our reflections.

She then replies to her own tweet, saying: "I am the person many had mixed feelings about. Black, fat, potty mouthed, unpolished, queer, loaded w/invisible disabilities, a woman, high school dropout, "problematic" ... And to those people, I am powerful, 
worthy, captivating, beautiful, intelligent ... infinite." In a final tweet, she implores her followers to: "[not] stop here. Push other platforms to change the narrative. I promise there's more people out there waiting to have their stories told." Clearly, beyond motivating others to exercise, she is an activist who motivates many people to change a world where the intersectional effects of colonialism limit opportunities.

\subsubsection{Transparency about Food, Mental Health, and Resistance}

Another way the two runners amplify their visibility and resist colonial knowledge is through their insistence on showing, through their social media profiles, the importance of food and its connection to mental health. Indeed, Latoya Shauntay Snell is a chef by trade with a brand called Running Fat Chef, and so food comprises a large part of her social media presence. For example, in November 2020, Latoya Shauntay Snell tweeted the following: "This week was slightly stressful. Dessert first, main course second + possibly a new tequila recommended by my wine shop. In this pic: Bourbon crème Bread Pudding w/Cookie Dough Ice Cream + Caramel Redux Sweet Teriyaki Beef Stir Fry ... " In January 2020, Mirna Valerio uploaded an Instagram post in which she details having had a long day of athletic training that finished off with cross-country skiing: "Snow was super sticky today but it was an excellent workout. CUE IMMEDIATE RAVENOUS HUNGER [sic]." Based on these posts, it appears as though both women are unapologetic with their food and drink choices and honest about feeling hungry and acting on these hunger cues without restraining themselves in connection to, not in spite of, running/exercise.

Mirna Valerio explained an instance where she was asked on Instagram:

"how many KCAL I burn/eat for someone at such a weight who is so active. I deleted the comment (because it wasn't really a question) immediately because I don't want that in my feed, in my life, shadowing my activities with judgement, and intending to make me question my body."

She then goes on to add: "Some folks think that they are entitled to comment on others' bodies, that they are entitled to project their own ideas of body image ... that someone's weight, body size, or shape is a mathematical equation to be solved". Rather than question her calories, she also posted that: "The only questions I have for my body are, WHAT SPORT(S) DO YOU WANT TO DO TODAY? Or WHERE SHOULD WE ADVENTURE TODAY? or HOW DO YOU WANT TO REST TODAY? or HOW SHALL I NOURISH YOU TODAY? [sic]" These posts encapsulate the ways that Mirna Valerio continues to unapologetically embrace food, fatness, and fitness, even when regularly confronted by those who endorse the idea of the thin runner ideal.

Latoya Shauntay Snell is particularly open about her emotions, her health, and her running career. She is very candid about not always feeling her best; for example, in a December 2020 Instagram post, she shares that her body is in chronic pain three-quarters of the time and that "Endometriosis flares, sciatica, gastrointestinal issues and coughing fits from my bronchitis started affecting my mental state." In that same post, she goes on to say, "I cringe some days about the body positive movement because it's so visually focused that it almost gives no credit to the mental state, living with chronic conditions". In another post, Latoya Shauntay Snell expresses the challenges of living through racial unrest and a pandemic, "Running is a serious struggle this year ... I refuse to practice toxic positivity and pretend that everything's okay-it's not. I'll sit in this momentary bullsh*t, allow its ugliness to reveal itself at every run until something clicks." In a tweet on 25 September 2020, she openly shared her struggles related to being a Black woman in America, "We can be disgusted by a rigged system + still find moments to honor our happy, brilliant + exceptional Black selves. NOTE: I didn't say strong or brave. This is an overused term." Shauntay Snell, in adamantly refusing to practice toxic positivity and rejecting the use of the word strong, is actively rejecting what Beauboeuf-Lafontant elucidates as the 'strong Black woman' stereotype [78]. The 'rigged' system is one that medicalizes human diversity, creates hierarchies of bodies deemed to be defective, disgusting, queer, mad, and otherwise unwelcomed, and silences people who dare question the received powerful and prejudicial 
knowledge of the dominant culture $[10,15,79]$. The same colonial systems that created Apartheid, Jim Crow, and Indian Residential Schools created discrimination against fat Black women in America. To reject the toxicity and silencing while advocating for social justice is a form of decolonial activism.

Latoya Shauntay Snell and Mirna Valerio also often challenged those who were questioning or trying to correct their lifestyles. For example, in September 2020, Aubrey Gordon, Your Fat Friend (she/her/hers) @yrfatfriend, posted: "If you're tempted to use the phrase "struggles with their weight" to describe another person: Have they told you that they "struggle"? Or are they just fat?". In response to this, Mirna Valerio tweeted: "A few of the media things I have been in (news, tv shows) have titled my episodes/spots with this language and I have NEVER, EVER said that I struggle with my weight. This is definitely a euphemism and projection. Struggle implies a fight. That is definitely NOT what I am up to."

Latoya Shauntay Snell posted on Instagram in January 2021:

Dear people that like to come over to a fat woman's feed correcting things that you haven't mastered nor I hired you for, please mind your $\mathrm{f}^{* *}$ business. I am not here to be your beauty standard nor am I seeking a personal trainer to help me sculpt my body into an hourglass figure. I actually don't mind being shaped as an apple, octagon, a big booty box + I love doing my kettlebells on a damn bosu ball.

In that same month, one of her posts implored, "let me be fat in peace. We're only 6 days into the new year and some of y'all already tried it. Mind your business and leave my rolls alone." Posts such as these show how Shauntay Snell takes on the role of decolonial educator, actively teaching others about her boundaries, self-love, and knowledge that opposes colonial definitions.

In addition to being active on social media and having large followings there, the women also share their knowledge and experiences in other ways. Mirna Valerio previously had a blog, Fatgirlrunning, which became increasingly popular, and now uses the moniker Fatgirlrunning to share her writing on Women's Running Magazine instead. Valerio creates and delivers her own workshops and is a motivational speaker. Her engagements reflect her identity and experiences as a fat, Black runner, with topics ranging from Diversity, Equity, and Inclusion in the outdoor and fitness industries to body image. She is also the author of a book, Your Body is a Beautiful Work in Progress, and short films distributed through YouTube depict her journey as a runner who has been shamed for being fat and nevertheless perseveres in long-distance events [79].

Latoya Shauntay Snell partners with non-profits for speaking engagements and cohosts a podcast with fellow self-identified fat Black runner Martinus Evans called The Long Run, on which conversations generally center around race, the body, and running. The following is an excerpt from an interview Latoya Shauntay Snell did with Runners World about her reaction to being harassed for her weight during the New York City Marathon:

"I want to show people that you can be brave and bold in your own personal space, and that you should not be apologetic in taking up space- not just in the physical form, but in the power of your own voice. You should not have to apologize for being present and for speaking up, especially for people in marginalized communities, women, people of colour, people who are sometimes overlooked because of a disability."

Similarly, in Mirna Valerio's description of her book on her website, she pronounces the body as unapologetic, no matter what form it is in: "The body is fierce, beautiful, and unapologetic. It's meant to move through the world as it wishes: lifting, walking, and running, rolls and all. Love handles, bouncy boobs, curves, tummy, butt, back fat, and all." Therefore, it is evident that in both women's social media accounts, in interviews, and in their writing they are unapologetic practitioners of what Taylor refers to as 'radical self-love' [11]. 


\section{Discussion}

In understanding weight loss as a colonial project, defying the pressure for change or progress can be viewed as colonial resistance [22]. Rail cautioned against the perpetuation of discourses that prioritize having a 'normal' body, or eschew being fat, noting that such views are oppressive to those living in bigger bodies who are so often stigmatized and understood as representing 'ill-health' and improper, individual 'lifestyle choices' [80] (p. 232), where health and choice are also positioned as a means to productivity. Therefore, researchers and activists in these areas have spoken of ways to demedicalize and reconceptualize fatness and its meanings, and in doing so, reclaim fat identity [81]. Fat empowerment can be found within sport, where fat runners who receive "disapproving looks and unwarranted assumptions, ... [and] are constantly reminded that their bodies are unacceptable and need to be improved" can celebrate their size and achievements [40] (p. 140). Through their mere presence and athletic prowess, the assumed-to-be "undisciplined body also has the potential to disturb the dominant discourses of distance running and, as such, can be seen as a site of resistance" [40] (p. 140).

Examination of self-authored media representations reveals McGannon's understanding of critical discourse analysis, which points to the ways subject positions can be chosen, (re)negotiated, and changed depending on access to new and different discursive resources [59]. Mirna Valerio and Latoya Shauntay Snell, with their running achievements and social media presence, are very actively and publicly reclaiming fat identities, resisting misunderstandings of what fat bodies can do, and producing new and different discursive resources for their respective communities.

Moreover, their words, photos, videos, and actions move beyond pro-fatness. They explicitly operate within a pro-Black, pro-women, pro-sport decolonial framework that centers the typically marginalized 'thick Black women' as knowledgeable, which, GentlesPeart ascertains is an act of decolonization in itself [42]. What the runners share through their social media defies and resists the dehumanization of 'thick' Black female bodies, while endorsing and engaging in what Gentles-Peart has coined emancipatory thick body politics, that is, "activities that aim to promote radical ethics of self-love that restore wounded voluptuous Black female bodies and resist social and psychological oppressions that operate on and through these bodies" through everyday Black women's decolonizing work [42] (p. 309). Black women "actively subverted the dominant construction of true femininity as white and thin" by rejecting cultural texts and related dominant notions about who has the power to know that tend to privilege white men and medical, ableist knowledge of bodies [42] (p. 316). Similarly, a study by Barned and O'Doherty, found that a sample of Jamaican women achieved health by disidentifying with colonial ideals, moving outside of Western standards, and reclaiming their bodies as beautiful and healthy at any size [81], and Bahra offers an autoethnographic description of fatness and racialization that affirms difference; allowing herself to exist without the need to transform is emancipatory [82]. These examples clarify what Sonia Renee Taylor articulates: in a world where we are confronted by "terrorism against our bodies to perpetuate body shame and to support body-based oppression," fat bodies that profess self-love and refuse to emphasize weight transformations-despite being athletic — can be understood as radical and decolonial [11] (p. 48). For example, in the language, images, and hashtags Mirna Valerio and Latoya Shauntay Snell use in their social media, they resist the need to transform, thereby resisting colonial temporality.

With the increased societal focus in recent decades on the biomedicalized 'obesity pandemic,' certain bodies have become framed as risky or at risk. However, the fields of critical health research and fat studies have continued to fight back against these biomedical foci. Indeed, various researchers have advocated for alternative discourses when framing the body and health, including understanding fat as a political issue and fat bodies as "revolting" in two senses. While they are labeled as abhorrent, by accepting their size, they also revolt against limited Western ideals and understandings of health and beauty $[13,83,84]$, as they disidentify with the colonial or Eurocentric idea of the thin ideal, one that equates feminine 
beauty with whiteness $[42,85]$. Mirna Valerio and Latoya Shauntay Snell's emancipatory thick body politics and radical self-love actively subvert such dominant constructions by very publicly and unapologetically refusing to be silenced or invisibilized in a culture that strives to do just that. Instead, they act as educators, advocates, and knowledge producers, sharing their journeys, reactions to injustice, and performances of freedom, refusing to shape themselves into thin, and thereby culturally sanctioned as feminine, bodies, which Gentles-Peart contends is a form of decolonization [42].

By being so publicly and unapologetically visible and by actively taking up space, Latoya Shauntay Snell and Mirna Valerio defy invisibility through their activism. As Ngate explains, "colonizers had no trouble at all making the colonized invisible, erasing them as subjects of any kind of meaningful discourses" [86] (p. 49). However, these acts were never permanent. The dynamic nature of (in)visibilization may be explained by 'seeing' visibility as an ambiguous social dimension, contingent upon "contextual social, technical and political complexes or regimes [66] (p.186)." Visibility may have empowering effects when it is understood as recognition, such as through online articles that exalt Valerio and Shauntay Snell as 'Inspiring Fitness Women to Follow,' though it may have disempowering effects when experienced as control, such as surveillance of their food choices [66]. Mirna Valerio and Latoya Shauntay Snell, with their online presences, illustrate the ways that visibility, once achieved, can be turned into social action.

In line with Joseph's contention that resistance is a corporeal act, dependent on kinaesthetic action and an audience [87], by running in fat bodies and writing about their resistance to colonial norms, these two women use their visibility for decolonial resistance. A Black feminist theoretical lens suggests that when Black women are not being rendered invisible, they are made hypervisible. This hypervisibility is often demonstrated through the ways in which Black female bodies are stereotyped and framed as abnormal, hypersexual, or as socially deviant [35]. Mirna Valerio and Latoya Shauntay Snell re-claim this visibility, making themselves hypervisible on their own terms, with the aim of empowering others around them. As such, in a decolonizing sense, they are also effectively un- "erasing them[selves] as subjects of any kind of meaningful discourses" [86] (p. 49). Self-authored hypervisibility has long been a tool of queer and crip performers, who demonstrate to the world their capacity to resist dominant projections of their (in)abilities [88,89]. Such affirmative politics of difference through visible performance foster what Rice refers to as "a move away from cultural practices of enforcing norms" and related attempts to "regulate bodily diversity" [90] (p. 392).

This case study shows what Shang suggests in his analysis of colonial legacies in African literary texts: "engaging notions of corporeal difference, [and] reasserting the humaneness of subject bodies" are important forms of decolonization [28] (p. 14). While openly addressing their experiences with corporeal difference, disability, illness, and fitness, Mirna Valerio and Latoya Shauntay Snell reject the notion of the strong Black woman that Beauboeuf-Lafontant outlines [78]. This cultural construct, often used by Black women to cope with race- and gender-based discrimination in their daily lives dates back to the period of slavery when African American women were portrayed as both psychologically and physically strong, allowing European Americans to justify vile treatment. Those who were enslaved socialized their daughters to be strong, to prepare them for future violent and inhumane lives in slavery [91]. The strong Black woman stereotype does not allow for open discussions of distress, vulnerability, or the burden of caring for others and can ultimately cause women to hide internal struggles [31,92]. Therefore, by openly speaking about her physical health conditions, her mental ill-health, and racism, not only does Latoya Shauntay Snell resist disempowerment, but she also redefines characteristics that are outlined by Graham and Clarke as valued in Western societies, such as self-sufficiency and resilience [92]. Further, by refusing to be silent and engaging in conversations around these issues, she effectively distances herself from the neoliberal, Western "glamorized myth of independence and individualism" and instead embraces vulnerability and interdependency, demonstrating "a radical act of resistance" 
and a "powerful tool for healing" for Black women [93] (p. 38). Rather than a confessional, this is an empowering manifesto for celebrating the full range of what human bodies are and can do.

\section{Conclusions}

It has been suggested that sport and activity can provide contexts for personal empowerment, inspiration of others, and achievement of wellbeing, which can be vital in resisting and regenerating from the effects of colonialism $[38,69,70,94]$. This study, guided by fat studies, Black feminist, and de-colonial frameworks, established that fat Black female runners, Mirna Valerio and Latoya Shauntay Snell, strive to resist the effects of colonialism on a daily basis by actively sharing their running journeys through social media. These runners reject emphases on bodyweight transformation, produce and translate knowledge, and refuse to be silenced or invisibilized. In doing so, these women are engaging in decolonial resistance, uncoupling from "the colonial matrix of power" [1] (p. 178) in order to redefine "the materiality of the body itself" [2] (p. 9).

The current work adds another angle to Ifekwunigwe's analysis of Black female excellence in sport, which sought to "celebrate and affirm the resilience and the resistance of black women in general and black female athletes in particular" [47] (p. 125). Our analysis of Valerio and Shauntay Snell also sheds light on the intersectional and embodied experiences of differences that Ifekwunigwe emphasizes and adds an amateur athlete perspective to the current Black women in sport literature, which has up to this point largely focused on professional Black female athletes [47]. Moreover, it intervenes in the Black 'obese' women literature [5-8] to offer a missing perspective from the fit fat woman. Taken together, these findings align with Hobson's work, which used a Black feminist disability approach to call for an aesthetic that recognizes the Black female body as beautiful [34]. This case study of fat Black women runners elucidates the intersectional, decolonial fight against misogynoir, ableism, and anti-fat bias.

Author Contributions: Conceptualization, G.A.-F.; methodology, G.A.-F.; formal analysis, G.A.-F. and J.J.; investigation, G.A.-F. and J.J.; resources, G.A.-F. and J.J.; data curation, G.A.-F. and J.J.; writing - original draft preparation, G.A.-F. and J.J.; writing—revising, reviewing, and editing, G.A.-F. and J.J.; visualization, G.A.-F. and J.J.; supervision, J.J.; project administration, J.J. All authors have read and agreed to the published version of the manuscript.

Funding: G.A.F. is supported by Canadian Institutes of Health Research (CIHR) funding. 201810GSD422091-288088.

Data Availability Statement: Data is available: for Mirna Valerio at https: / twitter.com/themirnavator (accessed on 14 July 2021) and https:/ / www.instagram.com/themirnavator/ (accessed on 14 July 2021) and for Latoya Shauntay Snell at https://twitter.com/latoyashauntay (accessed on 14 July 2021) and https:/ / www.instagram.com/iamlshauntay/ (accessed on 14 July 2021).

Acknowledgments: The authors would like to acknowledge Latoya Shauntay Snell and Mirna Valerio for their public advocacy that made this paper possible and research assistantship from Alyssa McQuaid (University of Toronto).

Conflicts of Interest: The authors declare no conflict of interest.

\section{References}

1. Mignolo, W.D. Epistemic disobedience, independent thought and decolonial freedom. Theory Cult. Soc. 2009, 26, $159-181$. [CrossRef]

2. Tate, S.A. Black Women's Bodies and the Nation. 2015. Available online: http://www.palgraveconnect.com/doifinder/: $10.1057 / 9781137355287$ (accessed on 14 July 2021).

3. Syed, I.U. In biomedicine, thin is still in: Obesity surveillance among racialized, (im)migrant, and female bodies. Societies 2019, 9, 59. [CrossRef]

4. Lewis, S.T.; Van Puymbroeck, M. Obesity-stigma as a multifaceted constraint to leisure. J. Leis. Res. 2008, 40, 574-588. [CrossRef]

5. Frieden, T.R. CDC Health Disparities and Inequalities Report (CHDIR). Minority Health. CDC. Available online: https://www. cdc.gov / minorityhealth/CHDIReport.html (accessed on 30 May 2021). 
6. Lincoln, K.D.; Abdou, C.M.; Lloyd, D. Race and Socioeconomic Differences in Obesity and depression among black and non-hispanic white Americans. J. Health Care Poor Underserved 2014, 25, 257-275. [CrossRef]

7. Williams, D.R. Racial/ethnic variations in women's health: The social embeddedness of health. Am. J. Public Health 2002, 92, 588-597. [CrossRef]

8. Noonan, A.S.; Velasco-Mondragon, H.E.; Wagner, F.A. Improving the health of African Americans in the USA: An overdue opportunity for social justice. Public Health Rev. 2016, 37, 1-20. [CrossRef]

9. Meadows, A.; Daníelsdóttir, S. What's in a Word? On Weight Stigma and Terminology. Available online: https://www.frontiersin. org/articles/10.3389/fpsyg.2016.01527/full (accessed on 30 May 2021).

10. Wann, M. The Fat Studies Reader: An Invitation to Revolution; Rothblum, E., Solovay, S., Eds.; NYU Press: New York, NY, USA, 2009.

11. Taylor, S.R. The Body Is Not an Apology, Second Edition: The Power of Radical Self-Love; Berrett-Koehler Publishers: Oakland, CA, USA, 2021.

12. Saguy, A.C.; Ward, A. Coming out as fat: Rethinking stigma. Soc. Psychol. Q. 2011, 74, 53-75. [CrossRef]

13. LeBesco, K. Revolting Bodies? The Struggle to Redefine Fat Identity; University of Massachusetts Press: Amherst, MA, USA, 2004.

14. Crenshaw, K. Demarginalizing the intersection of race and sex: A black feminist critique of anti-discrimination doctrine, feminist theory, and antiracist politics, 1989. In Feminist Legal Theory; Routledge: London, UK, 1991.

15. Collins, H.P. Intersectionality as Critical Social Theory. Available online: http://read.dukeupress.edu/books/book/2613 /Intersectionality-as-Critical-Social-Theory (accessed on 29 May 2021).

16. Burgard, D. Fat Studies in Health and Medicine: What Is "Health at Every Size"? Rothblum, E., Solovay, S., Eds.; NYU Press: New York, NY, USA, 2009; pp. 41-53.

17. Shaw, A.E. The Embodiment of Disobedience: Fat Black Women's Unruly Political Bodies; Lexington Books: Washington, DC, USA, 2006; p. 161.

18. Bailey, M. Misogynoir in medical media: On caster Semenya and R. Kelly. Catal. Fem. Theory Technoscience 2016, 21, 1-31. [CrossRef]

19. Strings, S. Fearing the black body: The racial origins of fat phobia. Soc. Forces 2020, 99, e3. [CrossRef]

20. Forth, C.E. Fat, desire and disgust in the colonial imagination. Hist. Work. J. 2012, 73, 211-239. [CrossRef]

21. Guthman, J.; Dupuis, M. Embodying neoliberalism: Economy, culture, and the politics of fat. Environ. Plan. Soc. Space 2006, 24, 427-448. [CrossRef]

22. Fox, R. Against progress: Understanding and resisting the temporality of transformational weight loss narratives. Fat Stud. 2017, 7, 216-226. [CrossRef]

23. Rose, D.B. Reports from a Wild Country: Ethics for Decolonisation; UNSW Press: Randwick, Australia, $2004 ;$ p. 252.

24. Bridel, W.; Rail, G. Sport, sexuality, and the production of (resistant) bodies: De-/Re-Constructing the meanings of gay male marathon corporeality. Sociol. Sport J. 2007, 24, 127-144. [CrossRef]

25. Spillers, H.J. Black, White, and in Color: Essays on American Literature and Culture; University of Chicago Press: Chicago, IL, USA, 2003; p. 571.

26. LeBesco, K. Neoliberalism, public health, and the moral perils of fatness. Crit. Public Health 2011, 21, 153-164. [CrossRef]

27. Thompson, C. Neoliberalism, soul food, and the weight of black women. Fem. Media Stud. 2015, 15, 794-812. [CrossRef]

28. Shang, G. A question of the body: Colonial legacies and postcolonial imaginaries of power in African literary texts. Int. J. Engl. Lit. 2016, 7, 143-151.

29. Collins, H.P. Learning from the outsider within: The sociological significance of black feminist thought. Soc. Probl. 1986, 33, s14-s32. [CrossRef]

30. Awad, G.H.; Norwood, C.; Taylor, D.S.; Martinez, M.; McClain, S.; Jones, B.; Holman, A.; Chapman-Hilliard, C. Beauty and body image concerns among African American college women. J. Black Psychol. 2014, 41, 540-564. [CrossRef]

31. Collins, P.H. Black Feminist Thought. 2002. Available online: https://doi-org.myaccess.library.utoronto.ca/:10.4324/9780203900 055 (accessed on 14 December 2020).

32. Strings, S. Obese black women as "social dead weight": Reinventing the "diseased black woman" signs. J. Women Cult. Soc. 2015, 41, 107-130. [CrossRef]

33. Mattoscio, M. What's in a face? Sara Baartman, the (post)colonial gaze and the case of Venus Noire, 2010. Fem. Rev. 2017, 117, 56-78. [CrossRef]

34. Hobson, J. The "batty" politic: Toward an aesthetic of the black female body. Venus Dark 2018, 18, 87-112. [CrossRef]

35. Mowatt, R.A.; French, B.H.; Malebranche, D.A. Black/female/body hypervisibility and invisibility. J. Leis. Res. 2013, 45, 644-660. [CrossRef]

36. Young, J. The re-objectification and re-commodification of Saartjie Baartman in Suzan-Lori Parks's Venus. Afr. Am. Rev. 1997, 31, 699-708. [CrossRef]

37. Usiekniewicz, M. Dangerous bodies: Blackness, fatness, and the masculinity dividend. J. Queer Stud. 2016, 11, 19-45.

38. Bale, J. Sport as power: Running as resistance? In Entanglements of Power, 1st ed.; Routledge: London, UK, $2000 ;$ p. 16.

39. Bridel, W.; Markula, P.; Denison, J. Endurance Running: A Socio-Cultural Examination; Routledge: London, UK, 2016 ; p. 273.

40. Chase, L.F. Running big: Clydesdale runners and technologies of the body. Sociol. Sport J. 2008, 25, 130-147. [CrossRef]

41. Sanders, R. The Color of Fat: Racial Biopolitics of Obesity. 2014. Available online: https://digital.lib.washington.edu:443/ researchworks/handle/1773/24980 (accessed on 30 May 2021). 
42. Gentles-Peart, K. "Fearfully and wonderfully made": Black Caribbean women and the decolonization of thick black female bodies. Fem. Psychol. 2020, 30, 306-323. [CrossRef]

43. Saguy, A.C.; Gruys, K. Morality and health: News media constructions of overweight and eating disorders. Soc. Probl. 2010, 57, 231-250. [CrossRef]

44. Kendall, M. Hood Feminism: Notes from the Women That a Movement Forgot; Viking: New York, NY, USA, 2020.

45. Hull, G.T.; Bell-Scott, P.; Smith, B. All the Women Are White, all the Blacks Are Men, but Some of Us Are Brave: Black Women's Studies; The Feminist Press at the City University of New York: New York, NY, USA, 1982; p. 401.

46. Hooks, B. Talking Back: Thinking Feminist, Thinking Black, 2nd ed.; New York Routledge: New York, NY, USA, $2014 ;$ p. 208.

47. Ifekwunigwe, J.O. "And Still Serena Rises": Celebrating the Cross-Generational Continuities of Black Feminisms and Black Female Excellence in Sport. 2017. Available online: http://link.springer.com/10.1057/978-1-137-53318-0_8 (accessed on 30 May 2021).

48. Lovejoy, M. Disturbances in the social body: Differences in body image and eating problems among African American and white women. Gend. Soc. 2001, 15, 239-261. [CrossRef]

49. Cameron, N.O.; Muldrow, A.F.; Stefani, W. The weight of things: Understanding African American women's perceptions of health, body image, and attractiveness. Qual. Health Res. 2018, 28, 1242-1254. [CrossRef]

50. Bonilla, Y.; Rosa, J. Ferguson: Digital protest, hashtag ethnography, and the racial politics of social media in the United States. Am. Ethnol. 2015, 42, 4-17. [CrossRef]

51. Lawson, C.E. Platform vulnerabilities: Harassment and misogynoir in the digital attack on Leslie Jones. Inf. Commun. Soc. 2018, 21, 818-833. [CrossRef]

52. Nakamura, L. The unwanted labour of social media: Women of colour call out culture as venture community management. New Form. 2015, 86, 106-112. [CrossRef]

53. Berry-McCrea, E.L. "To my girls in therapy, see imma tell you this for free"-Black millennial women speaking truth to power in and across the digital landscape. Meridians 2018, 16, 363-372. [CrossRef]

54. Razack, S.; Joseph, J. Misogynoir in women's sport media: Race, nation, and diaspora in the representation of Naomi Osaka. Media Cult. Soc. 2020, 43, 291-308. [CrossRef]

55. Sveinson, K.; Hoeber, L.; Heffernan, C. Critical discourse analysis as theory, methodology, and analyses in sport management studies. J. Sport Manag. 2020, 1, 1-11. [CrossRef]

56. Lafrance, M.N. Reproducing, resisting and transcending discourses of femininity: A discourse analysis of women's accounts of leisure. Qual. Res. Sport Exerc. Health 2011, 3, 80-98. [CrossRef]

57. McGannon, K.R.; Spence, J.C. Speaking of the self and understanding physical activity participation: What discursive psychology can tell us about an old problem. Qual. Res. Sport Exerc. 2010, 2, 17-38. [CrossRef]

58. Jette, S. Fit for two? A critical discourse analysis of oxygen fitness magazine. Sociol. Sport J. 2006, 23, 331-351. [CrossRef]

59. McGannon, K.R. Critical discourse analysis in sport and exercise: What, why and how. In Routledge Handbook of Qualitative Research in Sport and Exercise; Routledge: London, UK, 2016.

60. The Mirnavator. Available online: https://www.instagram.com/themirnavator/?hl=en (accessed on 10 January 2021).

61. The Mirnavator, Twitter. Available online: https:/ / twitter.com/TheMirnavator (accessed on 15 January 2021).

62. Latoya Shauntay Snell, Twitter. Available online: https://twitter.com/latoyashauntay (accessed on 15 January 2021).

63. Latoya Shauntay Snell. Available online: https://www.instagram.com/iamlshauntay/ (accessed on 10 January 2021).

64. Mehlman-Petrzela, N. Jogging Has Always Excluded Black People. Available online: https://www.nytimes.com/2020/05/12 /opinion/running-jogging-race-ahmaud-arbery.html (accessed on 30 May 2021).

65. Razack, S.H. Settler colonialism, policing and racial terror: The police shooting of loreal tsingine. Fem. Leg. Stud. 2020, 28, 1-20. [CrossRef]

66. Brighenti, A.M. Visibility in Social Theory and Social Research; Palgrave Macmillan: London, UK, 2010.

67. Lyon, D. Surveillance Society: Monitoring Everyday Life; McGraw-Hill Education: London, UK, 2001; p. 207.

68. What It's Really Like to Parent a Child with a Chronic Illness. HuffPost. 2018. Available online: https:/ / www.huffpost.com/ entry/what-its-really-like-to-parent-a-child-with-a-chronic-illness_n_5a3c3a7ce4b06d1621b32a46 (accessed on 30 May 2021).

69. Bale, J.; Sang, J. Kenyan Running: Movement Culture, Geography, and Global Change; Psychology Press: East Sussex, UK, 1996 ; p. 236.

70. McGuire-Adams, T.D.; Giles, A.R. Anishinaabekweg dibaajimowinan (stories) of decolonization through running. Sociol. Sport J. 2018, 35, 207-215. [CrossRef]

71. About Us Black Girls Run. 2020. Available online: https:/ /blackgirlsrun.com/about (accessed on 31 May 2021).

72. Black Girls Do Run UK. Available online: https:/ / www.instagram.com/blackgirlsdorunuk/ (accessed on 10 January 2021).

73. Aitchison, C. New cultural geographies: The spatiality of leisure, gender and sexuality. Leis. Stud. 1999, 18, 19-39. [CrossRef]

74. McCoy, J. Find Your Voice and You Can Move Mountains. Available online: https://www.runnersworld.com/runners-stories/a3 4273812/ find-your-voice-and-you-can-move-mountains (accessed on 30 May 2021).

75. Wilson, K. 5 Inspiring “Curvy Fit” Influencers We're Following (and Loving!)—Essence 2021. Available online: https://www. essence.com/lifestyle/health-wellness/curvy-fit-influencers-to-follow (accessed on 30 May 2021).

76. Inspiring Fitness Women to Follow on Instagram. Available online: https://www.glamour.com/story/inspiring-fitness-womento-follow-on-instagram (accessed on 30 May 2021). 
77. Jones, K. 10 People to Follow in 2021. Available online: https://globalsportmatters.simplecast.com/episodes/10-people-tofollow-in-2021 (accessed on 31 May 2021).

78. Beauboeuf-Lafontant, T. Behind the Mask of the Strong Black Woman: Voice and the Embodiment of a Costly Performance; Temple University Press: Philadelphia, PA, USA, 2009; p. 195.

79. REI Presents: The Mirnavator. Available online: https:/ /www.youtube.com/watch?v=c5-CSQcYeXk (accessed on 14 July 2021).

80. Rail, G. The birth of the obesity clinic: Confessions of the flesh, biopedagogies and physical culture. Sociol. Sport J. 2012, 29, 227-253. [CrossRef]

81. Barned, C.; O'Doherty, K. Understanding fatness: Jamaican women's constructions of health. Fat Stud. 2021, 8, 24-42. [CrossRef]

82. Bahra, R.A. "You can only be happy if you're thin!" Normalcy, happiness, and the lacking body. Fat Stud. 2018, 7, 193-202. [CrossRef]

83. Beausoleil, N.; Ward, P. Fat panic in Canadian public health policy: Obesity as different and unhealthy. Radic. Psychol. 2009, 8, 5-25.

84. Braziel, J.E.; LeBesco, K. Bodies Out of Bounds; University of California Press: Berkeley, CA, USA, 2001.

85. Pearce, V.; Dibb, B.; Gaines, S.O. Body Weight Perceptions, Obesity and Health Behaviours in Jamaica. Available online: http:/ / bura.brunel.ac.uk/handle/2438/15101 (accessed on 30 May 2021).

86. Ngate, J. African Literature: An Anthology of Criticism and Theory. Available online: https://www.wiley.com/en-us/African+ Literature\%3A+An+Anthology+of+Criticism+and+Theory-p-9781405112000 (accessed on 14 December 2020).

87. Joseph, J. Flash Mob, Canadian Multiculturalism, and the Politics of Belonging; Stolar, B., Lindgren, A.C., Sacchetti, C., Eds.; University of Toronto: Toronto, ON, Canada, 2021; pp. 187-202.

88. Thorneycroft, R. Crip theory and mad studies: Intersections and points of departure. Can. J. Disabil. Stud. 2020, 9, 91-121. [CrossRef]

89. Muñoz, J.E. Cruising Utopia: The Then and There of Queer Futurity; New York University Press: New York, NY, USA, 2009.

90. Rice, C. Rethinking fat: From bio to body becoming pedagogies. Cult. Stud. Crit. Methodol. 2015, 15, 387-397. [CrossRef]

91. West, L.M.; Donovan, R.A.; Daniel, A.R. The price of strength: Black college women's perspectives on the strong black woman stereotype. Women Ther. 2016, 39, 390-412. [CrossRef]

92. Graham, R.; Clarke, V. Staying strong: Exploring experiences of managing emotional distress for African Caribbean women living in the UK. Fem. Psychol. 2021, 31, 140-159. [CrossRef]

93. Stewart, C.P. The mule of the world: The strong black woman and the woes of being independent knots. Undergrad. J. Disabil. Stud. 2017, 3, 31-39.

94. Ritenburg, H.; Leon, A.E.; Linds, W.; Nadeau, D.M.; Goulet, L.M.; Kovach, M.; Marshall, M. Embodying de-colonization: Methodologies and indigenization. Int. J. Indig. Peoples 2014, 10, 67-80. 